\title{
EL MOVIMIENTO ESTUDIANTIL DE 1968: ECONOMÍA, REBELIÓN Y ROMANTICISMO
}

\author{
Dr. Jorge A. Salas-Plata Mendoza \\ Departamento de Ing. Civil y Ambiental \\ Instituto de Ingeniería y Tecnología \\ Universidad Autónoma de Ciudad Juárez \\ Email: jsalas@uacj.mx
}

\section{RESUMEN}

En México, las décadas de 1950 y 1960 se caracterizaron por un bajo desempleo, rápido crecimiento e inflación estable, aunque no todos los efectos de este periodo fueron buenos. La estrategia de desarrollo estabilizador no benefició a las grandes masas de población en rápido crecimiento. A fines de la década de los sesenta, la política en México estaba marcada por la corrupción, el caudillismo y el disgusto social. Los estudiantes no encontraron las mejores condiciones materiales para la realización de sus estudios, ni la clase de educación que buscaban en las universidades. Y cuando se graduaban de estas, les resultaba cada vez más difícil encontrar trabajo. El Estado mexicano no pudo integrar adecuadamente a la economía a este grupo social y tampoco pudo controlarlo del todo. Lo anterior fue produciendo descontento entre la población estudiantil mexicana que rápidamente adquirió conciencia política. El pliego petitorio del movimiento juvenil constituyó una bandera que clamaba justicia y rechazaba la represión. Fue una tendencia anti represiva en su origen que creció y se transformó en política. Como los jóvenes de las barricadas de un mundo transformado ya en aldea global, las y los estudiantes mostraron creatividad, conciencia política, idealismo, espontaneidad, inconformismo radical y agresividad.

Palabras clave: Desarrollo estabilizador, conciencia política, movimiento estudiantil, romanticismo.

\section{INTRODUCCIÓN}

El movimiento estudiantil de 1968 en México se llevó a cabo en un contexto en el que el PRI se hallaba en sus mejores momentos. El partido en el poder contaba con una gran estabilidad política. Controlaba corporativamente el movimiento obrero y manipulaba a los campesinos mediante una reforma agraria que, a pesar de ser cada vez más insuficiente, le daba márgenes de maniobra considerable. Desde el punto de vista económico, el capitalismo mexicano presenciaba un auge formidable que ya nunca pudo repetir. Los altos índices de crecimiento en la industria y en la agricultura, estabilidad financiera, mínimo endeudamiento, entre otros logros, configuraban lo que se dio en llamar "el milagro mexicano" de acuerdo con los apologistas del régimen. (Aguilar, 2018)

A pesar de haberse logrado un importante y sostenido crecimiento económico, la distribución de los beneficios de éste fue bastante desfavorable para la mayoría de la población. El patrón de acumulación de capital 
adoptado en México a partir de la década de los cincuenta del siglo pasado generó tres grandes contradicciones que terminaron por convertirse en fuertes limitantes a la continuidad del patrón de crecimiento: la concentración del ingreso, el desequilibrio externo y el déficit fiscal. (Citado por Aparicio, 2010, pag. 9)

Por otro lado, y desde el punto de vista del desarrollo sustentable, hay escepticismo justificado con relación a los indicadores monetarios como el Producto Interno Bruto (PIB) para evaluar hasta qué punto un país o región son sostenibles ambientalmente y por tanto económicamente. Ejemplo de lo anterior es el mismo periodo denominado "milagro mexicano ", en el que el PIB relativamente alto enmascaró las contradicciones inherentes a este periodo.

La industrialización de la economía mexicana en el periodo anteriormente mencionado ocasionó una migración enorme del campo a la ciudad y una demanda creciente de educación superior que las autoridades gubernamentales y sus instituciones no pudieron satisfacer del todo debido a los esquemas de corto plazo que caracterizan a la economía capitalista y a las políticas públicas.

Los estudiantes no encontraron las mejores condiciones materiales para la realización de sus estudios, ni la clase de educación que buscaban en las universidades. Y cuando se graduaban de estas, les resultaba cada vez más difícil encontrar trabajo al que con todo derecho aspiraban cuando comenzaban sus estudios universitarios. Lo anterior fue produciendo descontento entre la población estudiantil que rápidamente adquirió conciencia política por una razón muy simple: a diferencia de las organizaciones tradicionales del movimiento obrero que estaban profundamente burocratizadas y controladas desde hacía mucho tiempo por la sociedad burguesa, el medio estudiantil pudo liberarse de la manipulación constante y condicionamiento intelectual de los instrumentos de mediatización de la gran opinión pública al servicio de las élites del poder y del capitalismo. (Mandel, 2018)

De esta forma, un nuevo grupo social que buscaba mejores estándares de vida había emergido en el escenario político desde las fuentes mismas del sistema capitalista. El Estado mexicano no pudo integrar adecuadamente a la economía a este grupo y tampoco pudo controlarlo del todo. Aunque en el caso del movimiento estudiantil mexicano, su pliego petitorio pudiera reflejar una protesta muy elemental de aspiraciones democráticas básicas, visto a escala internacional, de manera desigual y combinada, fue una rebelión total que cuestionó no uno u otro aspecto de la sociedad existente, sino sus objetivos y medios. Fue una revuelta contra el estado industrial existente, tanto en contra de su estructura capitalista como del tipo de sociedad de consumo que creó. Esto se ligó a una resistencia sorprendente a cualquier cosa que viniese de arriba, al centralismo, a la modernización capitalista y al autoritarismo. Por último, el espíritu romántico del 68 no sólo constituyó la revuelta contra un sistema económico, social y político considerado inhumano, intolerable y opresivo, o de actos de protesta. También estuvo lleno de esperanzas utópicas y de sueños libertarios. La reivindicación del derecho a la subjetividad fue unida inseparablemente al impulso anticapitalista radical y al ímpetu antiburocrático del socialismo real que cruzó de un extremo al otro el movimiento del 68. (Lowy, 2018). 


\section{EL MODELO DE DESARROLLO ESTABILIZADOR}

La segunda guerra mundial provocó una mayor demanda europea y norteamericana de bienes primarios y manufacturados producidos en los países periféricos, situación que condujo a un mayor crecimiento de las exportaciones mexicanas y que se prolongó hasta 1945. Este auge exportador elevó las importaciones, lo que facilitó la creación de una industria sustentada en la demanda interna de maquinaria e insumos intermedios, que a su vez acentuó la tendencia al creciente desequilibrio externo en la cuenta corriente de la balanza de pagos. Durante la década 1940-1950, la economía mexicana inició la etapa de crecimiento sostenido que duraría hasta fines de los años sesenta.

El PIB creció a una tasa promedio anual superior al $7.5 \%$. Sin embargo, durante los años cuarenta y hasta 1955, la inflación se incrementó, lo que redujo los salarios reales. Esta reducción en el poder de compra real se vio compensada por el aumento del empleo, la migración hacia las ciudades y los cambios a ocupaciones mejor remuneradas. Entre 1958 y 1970 México experimentó un periodo de crecimiento sostenido que constituye el episodio más relevante en la historia económica del país, ya que la tasa real de crecimiento del PIB alcanzó un promedio de $6.7 \%$ anual, y la inflación, después de haber asimilado las repercusiones de la devaluación de 1954, descendió a un nivel promedio de $2.5 \%$ anual en los años sesenta.

El periodo se caracterizó por una prolongada estabilidad cambiaria que duró 20 años (1956-1976). En suma, las décadas de 1950 y 1960 se caracterizaron, en lo general, por un bajo desempleo, un rápido crecimiento y una inflación estable. Sin embargo, no todos los efectos de este periodo fueron buenos para la economía mexicana. (Aparicio, 2010).

"La estrategia de crecimiento económico conocida como el desarrollo estabilizador, que supuestamente se ha traducido en el 'milagro mexicano', no benefició a los intereses de las grandes masas de población en rápido crecimiento, para las cuales el costo de ese 'milagro’ representó una carga difícil de soportar. Esta estrategia de desarrollo condujo a la acumulación de contradicciones y tensiones socio políticas de magnitud desconocida durante todo el periodo posterior a la Revolución”. (Citado por Aparicio, 2010, pág. 8).

\section{LA CRISIS DEL SISTEMA POLÍTICO MEXICANO}

El pliego petitorio del movimiento estudiantil mexicano, que se hizo famoso, fue la bandera de este. Una bandera que clamaba justicia y rechazaba la represión. Fue un movimiento antirrepresivo en su origen que, apoyado por la población de la actual Ciudad de México, creció y se transformó en político. Los estudiantes levantaron la noble bandera de la Constitución (Fazio, 2018). Y así, el rechazo a la impunidad, la corrupción y el autoritarismo congénitos del Estado mexicano de los sesenta, los hizo hermanarse con el ideal del Che Guevara, no precisamente con sus ideas políticas, que la mayoría desconocía, sino por su solidaridad con las luchas de los pueblos oprimidos a escala mundial y las revoluciones sociales en curso en donde prevalecían las mismas condiciones de opresión. 
Por otro lado, el presidente de la república y su partido estaban fascinados por los juegos olímpicos que les sirvió como una pantalla para ocultar la realidad de un país adormecido por la reiteración del santo nombre de la revolución mexicana que había tenido su último aire de renovación a comienzos de los años cuarenta. México era un país de 45 millones de habitantes, donde más de 20 millones, en su mayoría campesinos analfabetos, vivían sojuzgados en la miseria y sin esperanza posible de que algunos de los logros de la hazaña de Villa y Zapata los alcanzara algún día.

En 1968 casi el 60 por ciento de la población mexicana era menor de 25 años (Fazio, 2018). Para esa masa de jóvenes la revolución mexicana sólo existía en la abundante propaganda oficial y en las versiones de sus padres. El México real tenía pies de barro. Estaba marcado por la corrupción, el caudillismo y un conformismo paralizante. El patrón mandaba en la empresa y en los sindicatos. Los líderes “charros” se eternizaban y se convertían en diputados y senadores millonarios. No había canales de representación popular. La justicia era deficiente y estaba permeada por influencias, compadrazgos, y la "mordida” (soborno) ya era una institución. Había un parlamento servil controlado por los priistas. La "dictadura de partido” contaba con una maquinaria asfixiante.

La oposición servía de comparsa al régimen. No había libertad de prensa ni de opinión. Salvo excepciones, los periodistas cobraban en la nómina del gobierno. Como corearon los estudiantes, era una "prensa vendida”, dócil. La política mexicana era oscura y secreta. El presidente en turno designaba a su sucesor, era el reino del "tapadismo" y el “dedazo”. Se vivía en una democracia simulada, sin ciudadanos. Mandaba la "familia revolucionaria”, y los “cachorros” en el poder irradiaban un paternalismo agobiante.
Todos los mexicanos eran tratados como menores de edad. Lo que estalló en julio del 68 fue el cansancio y el disgusto. El fastidio por la demagogia, la marginación, el enmudecimiento, la injusticia, el vacío y la claudicación. El grito estudiantil sacudió las arcaicas estructuras del sistema.

Todo México cabía en las demandas de los jóvenes sesentayocheros. Pero el movimiento fue demasiado amenazador y peligroso para un régimen autoritario. La movilización estudiantil llevaba al caos, fue la lectura desde la cúspide de la autoridad central. Según el gobierno y las élites del poder, una juventud idealista, ingenua, estaba siendo manipulada por los profesionales de la agitación y la violencia. Fue el discurso oficial: la "conjura comunista” como coartada.

El gobierno no podía hablar y menos dialogar; se necesitaba una mano de hierro. Con el sexenio de Gustavo Díaz Ordaz (1964-1970) la prepotencia priista llegó a niveles muy altos. Como secretario de Gobernación del gobierno del presidente anterior, Adolfo López Mateos (1958- 1964) y después él mismo como presidente, Díaz Ordaz fue el cerebro ejecutor de una de los ataques reaccionarios más feroces de América Latina enmedio de la guerra fría anticomunista llevada al extremo por los ocupantes de la Casa Blanca, Kennedy, Johnson y Nixon.

Bajo el pretexto de la lucha contra el comunismo, la represión a las luchas populares había cobrado muchas víctimas (el asesinato del líder campesino Rubén Jaramillo, su esposa embarazada y familiares), la terrible agresión a la huelga de los trabajadores ferrocarrileros en 1959 con miles de despedidos y decenas de dirigentes encarcelados durante años.

El famoso penal de Lecumberri era el símbolo obscuro de ese momento recluyendo a decenas de trabajadores, estudiantes, médicos, periodistas, profesores, intelectuales y en la 
cárcel de mujeres, también había presas políticas. Precisamente Demetrio Vallejo, el líder ferrocarrilero que llevaba casi diez años entre rejas se convertiría en el símbolo de los presos políticos cuya libertad fue una de las principales demandas del movimiento estudiantil-popular. (Aguilar, 2018).

\section{EL ROMANTICISMO EN EL MOVIMIENTO ESTUDIANTIL}

El Romanticismo no es sólo una escuela literaria de principios del siglo XIX (como todavía se puede leer en muchos libros), sino una de las principales formas de la cultura moderna. Como estructura sensible y visión del mundo, se manifiesta en todos los ámbitos de la vida cultural, a saber: la literatura, la poesía, el arte, la música, la religión, la filosofía, las ideas políicas, la antropología, la historiografía y otras disciplinas. (Lowy, 2018)
Como los jóvenes de las barricadas de un mundo transformado ya en aldea global, las y los estudiantes mostraron creatividad, conciencia de sí mismos, idealismo, espontaneidad, inconformismo radical y agresividad. Querían la gloria de una revolución de verdad, no pura máscara. (Lowy, 2018)

Testimonio de lo anterior fueron las siguientes expresiones en grafitis:

- "La barricada cierra la calle, pero abre el camino"

- "Cuando la asamblea nacional se convierte en un teatro burgués, todos los teatros burgueses deben convertirse en asambleas nacionales"

- "La imaginación no es un don, sino el objeto de conquista por excelencia"

- "Nuestra esperanza sólo puede venir de los sin esperanza."

- "Decreto el estado de felicidad permanente."

- "Prohibido prohibir. La libertad comienza por una prohibición."

- "Cambiar la vida. Transformar la sociedad."

- "Heráclito retorna. Abajo Parménides. Socialismo y libertad."

- "Contempla tu trabajo: la nada y la tortura forman parte de él."

- "La emancipación del hombre será total o no será."

- "La novedad es revolucionaria, la verdad también."

- "Las jóvenes rojas cada vez más hermosas."

- "La imaginación toma el poder."

- "En los exámenes, responda con preguntas."

- "Aprende a cantar la internacional."

- " "No puede volver a dormir tranquilo aquel que una vez abrió los ojos."

- " "Viva la comuna!"

- "Olvídense de todo lo que han aprendido. Comiencen a soñar."

- "Abajo el realismo socialista. Viva el surrealismo."

- " "La voluntad general contra la voluntad del general."

- "Si lo que ven no es extraño, la visión es falsa."

- "La belleza será revolucionaria o no será."

- " "La sociedad es una flor carnívora." 
- "Un pensamiento que se estanca es un pensamiento que se pudre."

- "Sean realistas: pidan lo imposible"

- " "Viva la comunicación! ¡Abajo la telecomunicación!"

- "Dios: sospecho que eres un intelectual de izquierda"

A falta de partidos políticos, las universidades habían terminado por ser los recintos donde los profesores y estudiantes expresaban libremente sus ideas. En el calor de la revuelta, los estudiantes mexicanos proclamaron: "UNAM, territorio libre de México”.

\section{DISCUSIÓN}

¿Cuál es, entonces, el legado del 68 hoy? Se puede estar de acuerdo en que el movimiento ha sido derrotado de forma permanente, que muchos de sus participantes y dirigentes se han hecho conformistas, y que el capitalismo (en su forma neoliberal) no solo triunfó a partir de 1980, sino que se convirtió en el único horizonte posible.

A pesar de lo anterior, parece que estamos asistiendo en los últimos años al desarrollo, a escala global, de un nuevo y vasto movimiento social, con un componente anticapitalista fuerte donde las nuevas generaciones rebeldes están inventando su propia combinación de deseos, utopías y subjetividad. Este esfuerzo estará lejos de ser homogéneo: mientras que sus participantes más moderados o pragmáticos seguirán creyendo en la posibilidad de regular el sistema, una gran parte de estos se manifestará abiertamente anticapitalista, y sus protestas podrán encontrar, como en el 68, una fusión única de las críticas romántica y marxista del orden capitalista, de sus injusticias sociales y su codicia mercantil.

Se pueden vislumbrar sin duda analogías con los 60 (las poderosas tendencias antiautoritarias o libertarias, por ejemplo), pero también diferencias importantes: la ecología y el feminismo, todavía incipientes en el 68, son ahora componentes centrales de la nueva cultura radical, mientras que las ilusiones en el "socialismo realmente existente" (soviético o chino) prácticamente han desaparecido (Lowi, 2018).

Las y los estudiantes mexicanos crearon su propia consigna: "2 de octubre no se olvida". La matanza de Tlatelolco fue un parteaguas. México también era América Latina. La amenaza al orden establecido había sido conjurada y pronto, de la mano de Pinochet y los Chicago Boys, irrumpiría el neoliberalismo en toda la región. El capitalismo había asimilado su crisis y se reestructuraba (Fazio, 2018).

En los cincuenta años que han transcurrido ciertamente el país ha cambiado mucho. Precisamente en este año en que se celebra el cincuentenario del inicio del Movimiento estudiantil-popular, tuvo lugar otro hito de la lucha del pueblo mexicano: en las elecciones generales del $1^{\circ}$ de julio un tsunami de más de 30 millones de votos de mexicanos y mexicanas propinaron su peor derrota histórica a la mancuerna partidaria representante de los amos de México: lo que la vox populi llama el PRIAN, la unión de los principales partidos de la derecha, el PRI y el PAN, que constituyeron durante los últimos treinta años el reciclamiento del régimen presidencialista. 
Tanto el PAN como el PRI se han derrumbado cayendo el segundo a una situación de irrelevancia política. La victoria electoral aplastante de Andrés Manuel López Obrador (AMLO) no significa todavía la desaparición del régimen. El régimen se encuentra en crisis con sus dos principales partidos sostenedores y apoyadores de los capitalistas seriamente dañados, tal vez sin remedio. El Movimiento de Regeneración Nacional (Morena) no es todavía un partido estructurado y en él se han refugiado muchos antiguos priistas y panistas, así como grupos heterogéneos provenientes de otras orientaciones políticas.

Constituye un gran conglomerado cuyo único común denominador es el caudillo dirigente. AMLO, el gran árbitro, se enfrenta a la tarea colosal de, al mismo tiempo, tener muy en cuenta a la por él mismo definida "mafia del poder”, que desde el mismo 2 de julio lo ha rodeado y aceptado como su nuevo guía, y a los millones de trabajadores y pueblo oprimido que le ha dado la victoria con inmensas esperanzas de que la situación del país va a experimentar un giro decisivo en favor del bienestar popular.

Cincuenta años después de 1968 se ha producido una situación nueva de la lucha política cuyos enigmas complejos y profundos son evidentes desde el primer mes de sucedido el giro electoral del $1^{\circ}$ de julio pasado. Se ha abierto un nuevo capítulo de la historia de México. No es exagerado afirmar que mucho de lo que sucede hoy tiene sus raíces en las alegres y audaces jornadas de las masas juveniles que recorrieron las calles de la capital de México y de otras ciudades del país, cimbrando los palacios y convocando al pueblo a unirse a su lucha por un México democrático y libertario. Fueron los héroes populares que se ganaron para siempre un lugar de honor en la memoria colectiva del pueblo mexicano. (Aguilar, 2018).

\section{CONCLUSIONES}

El movimiento estudiantil de los sesenta del siglo pasado no fue ocasionado solo por una crisis de la economía capitalista ya que tuvo lugar en la llamada era de los "treinta años gloriosos" (1945- 1975), años de crecimiento capitalista y prosperidad en México. Es importante señalar lo anterior para evitar el engaño de creer que las rebeliones anticapitalistas única o principalmente son el resultado solo de la recesión o de una crisis más o menos catastrófica de la economía: no existe una correlación directa entre las crisis económicas y el incremento o la disminución de las luchas, o revoluciones, anticapitalistas. A esto hay que añadir la protesta contra las guerras imperialistas y/o coloniales, y una poderosa ola de simpatía (no sin ilusiones "románticas") hacia los movimientos de liberación de los países oprimidos del Tercer Mundo. En otras palabras, hubo otro tipo de crítica anticapitalista, es decir, una crítica del desencanto, la falsedad y la miseria de la vida diaria, la deshumanización del mundo por la tecnocracia, la pérdida de autonomía y, por último, el autoritarismo opresivo de un gobierno jerárquico que en lugar de liberar las potencialidades humanas de forma autónoma, la auto-organización y la creatividad, sometía a los individuos a la "jaula de hierro" de la racionalidad instrumental y la mercantilización del mundo. Este romanticismo anticapitalista es más antiguo y tiene una base social mucho más amplia. Se encuentra no sólo entre los artistas, sino también entre intelectuales, estudiantes, mujeres y todo tipo de grupos sociales cuyo estilo de vida y cultura se ven afectados negativamente por el proceso destructivo de la modernización capitalista (Lowi, 2018). 


\section{BIBLIOGRAFÍA}

Aguilar, M. El 68 mexicano, 50 años después. Recuperado de http://www.sinpermiso.info/textos/el-68-mexicano-50-anos-despues

Aparicio, A. (2010). Economía Mexicana 1910-2010: Balance de un Siglo. 2010. Recuperado de file:///C:/Users/jartm/Documents/PONENCIA\%20FORO\%20ECONOMÍA/Economía.pdf

Fazio, 2018. El 68 mexicano: Tlatelolco, contra el país de pies de barro. Recuperado de http://www.sinpermiso.info/textos/el-68-mexicano-tlatelolco-contra-el-pais-depies-de-barro

Mandel, E. Cincuentenario del 68: Del levantamiento contra la universidad burguesa hacia el levantamiento contra la sociedad capitalista. Recuperado de http://www.sinpermiso.info/textos/cincuentenario-del-68-del-levantamientocontra-la-universidadburguesa-hacia-el-levantamiento-contra

Lowi. M. 2018. El romanticismo revolucionario de mayo del 68. Recuperado de http://www.sinpermiso.info/textos/el-romanticismo-revolucionario-de-mayo-del68 